\title{
Sikap Petani terhadap Pengolahan Kopi Robusta Berbasis Indikasi Geografis di Kabupaten Temanggung
}

\section{Farmer's Attitude Towards Robusta Coffee Processing Based on Geographical Indications in Temanggung Regency}

\author{
Nuning Setyowati*), Hanifah Ihsaniyati, Adhitya Pitara Sanjaya, Widianto
}

Universitas Sebelas Maret, Surakarta 57126, Indonesia

${ }^{*}$ E-mail Korespondensi: nuning_s@staff,uns.ac.id

Diterima: 10 November 2020 | Disetujui: 10 September 2021 | Publikasi Online: 20 September 2021

\begin{abstract}
Coffee is a superior commodity in Temanggung Regency. Post-harvest processing affects the quality of a coffee product. The Robusta Temanggung Coffee Geographical Indication Standard governs the standard of processing. This research aims to analyze the attitude of robusta coffee farmers towards GIs based coffee processing standards. The study uses a descriptive method. The respondents were 80 robusta coffee farmers in Temanggung Regency. Questionnaires are structured using a Likert scale. The data collection using random sampling techniques. The data analysis using the scoring method. The results showed that farmers had a good attitude towards GIs-based coffee processing standards, agreeing to GIs based sorting, drying, and storage processes. Farmers have not been motivated to measure coffee bean water content according to GIs standards due to facility constraints. Intensive education, motivation, facilities, and mentoring are required for farmers to implement GIs-based coffee processing standards.
\end{abstract}

Keywords: Coffee, coffee processing, geographical indication, quality, robusta

\begin{abstract}
ABSTRAK
Kopi merupakan komoditas unggulan di Kabupaten Temanggung. Mutu kopi salah satunya ditentukan oleh proses pengolahan pasca panen. Standar Indikasi Geografis (SIG) kopi robusta Temanggung mengatur tentang standar proses pengolahan kopi. Penelitian ini bertujuan untuk menganalisis sikap petani kopi robusta terhadap standar pengolahan kopi berbasis Indikasi Geografis (IG). Metode penelitian menggunakan metode deskriptif. Reponden penelitian adalah 80 petani kopi robusta di Kabupaten Temanggung. Kuesioner disusun secara terstruktur menggunakan skala Likert. Pengumpulan data menggunakan teknik random sampling dan analisis data menggunakan metode skoring. Hasil penelitian menunjukkan bahwa petani memiliki sikap baik terhadap standar pengolahan kopi berbasis IG, setuju terhadap proses sortasi, pengeringan dan penyimpanan berbasis IG. Petani belum termotivasi untuk melakukan pengukuran kadar air biji kopi sesuai standar IG karena kendala fasilitas. Diperlukan edukasi, motivasi, fasilitasi dan pendampingan intensif kepada petani untuk menerapkan standar pengolahan kopi berbasis IG.
\end{abstract}

Kata kunci: Kopi, indikasi geografis, mutu, pengolahan kopi, robusta

Content from this work may be used under the terms of the Creative Commons Attribution-ShareAlike 4.0 International. Any further distribution of this work must maintain attribution to the author(s) and the title of the work, journal citation and DOI.

Published under Department of Communication and Community Development Science, IPB University and in association with Perhimpunan Ahli Penyuluhan Pembangunan Indonesia.

E-ISSN: 2442-4110 | P-ISSN: 1858-2664 


\section{PENDAHULUAN}

Kabupaten Temanggung adalah salah satu wilayah di Jawa Tengah yang merupakan penghasil kopi terbesar di Jawa Tengah yaitu sebanyak 12.196,64 Ha pada tahun 2018 (Badan Pusat Statistik Provinsi Jawa Tengah, 2019). Kopi di Kabupaten Temanggung didominasi oleh jenis kopi robusta yaitu sebanyak 11.081,11 Ha (BPS Kabupaten Temanggung, 2019) dan tersebar di 11 kecamatan. Untuk menjaga mutu kopi robusta Temanggung, pemerintah telah memfasilitasi pendaftaran Indikasi Geografis (IG) untuk kopi robusta Temanggung pada tahun 2015 dan telah disetujui Kementerian Hukum pada tahun 2016. Pemerintah juga membentuk MPIGKRT (Masyarakat Perlindungan Indikasi Geografis Kopi Robusta Temanggung) untuk mengawal penerapan standar indikasi geografis oleh petani kopi robusta.

Mutu kopi robusta selain ditentukan oleh proses budidaya juga dipengaruhi oleh proses pengolahan pasca panen. Rasa dan aroma adalah atribut sensorik utama untuk membuat kopi menjadi salah satu minuman yang paling banyak dikonsumsi di dunia (Scholz et al., 2019; dos Santos et al., 2015). Praktik pasca panen yang berbeda memainkan peran penting dalam meningkatkan kualitas intrinsik kopi (Hamdouche et al., 2016; Duarte et al., 2010). Proses pengolahan kopi tersebut mulai dari metode pengolahan biji kopi, sortasi, pengeringan, pengukuran kadar air, dan penyimpanan biji kopi. Kopi yang diolah sesuai standar akan meningkatkan mutu dan daya saing (Atmaja et al., 2015; Yoga Priantara et al., 2017). Hal ini sejalan dengan hasil penelitian Pratiwi (2016) bahwa hasil pengolahan pasca panen kopi Temanggung belum diterima oleh pasar. Berdasarkan hasil penelitian Sumarjo \& Ihsaniyati (2020) diketahui jumlah petani yang sudah menerapkan indikasi geografis baru sebanyak $9.5 \%$.

Petani tidak mudah untuk serta merta menerapkan standar IG karena beberapa pertimbangan antara lain pemahaman yang masih relatif terbatas tentang standar IG, kekhawatiran terkait harga jual kopi robusta berstandar IG dan konsekuensi curahan waktu, tenaga dan biaya untuk menerapkan standar IG. Kondisi ini sejalan dengan hasil penelitian Murad et al. (2020) bahwa penanganan pasca panen kopi sulit diperbaiki karena tidak ada insentif harga, kopi bermutu baik dihargai hampir sama dengan kopi bermutu rendah. Petani merasa lebih untung menghasilkan kopi dengan mutu seadanya tanpa harus mengorbankan waktu dan biaya untuk memperbaiki mutu kopi yang dihasilkan. Kondisi ini menjadi tantangan tersendiri untuk memotivasi petani kopi robusta agar mau menerapkan standar IG khususnya pada proses pengolahan kopi. Dalam penelitiannya, Murad et al. (2020) menyatakan bahwa apabila kondisi ini tidak ditangani secara tepat maka ekspor kopi Indonesia akan turun dan pasar kopi domestik akan kelebihan penawaran yang pada gilirannya akan menurunkan harga kopi. Sebaliknya, menurut Sanaky \& Nashori (2018) praktek manajemen mutu pasca panen yang baik serta adanya lembaga yang mengelola dan memastikan manajemen mutu yang sesuai standar akan memberikan nilai tambah pada nilai produk, menjaga keberlanjutan sosial, ekonomi, lingkungan dan sumber daya alam yang ada.

Menurut Ajzen \& Fishbein (1981) perilaku seseorang dibentuk oleh sikap seseorang terhadap perilaku tersebut. Ketika sesorang menilai baik suatu perilaku maka akan ada kecenderungan bagi seseorang untuk melakukan perilaku tersebut dan sebaliknya. Demikian pula dalam perilaku adopsi standar IG kopi robusta Temanggung. Proses adopsi standar IG membutuhkan proses atau tahapan. Perilaku adopsi standar IG didahului oleh sikap terhadap standar IG. Ketika petani memiliki sikap positif terhadap standar IG maka akan mendorong terbentuknya niat untuk mengadopsi dan akhirnya mengadopsi standar IG. Kajian mengenai pasca panen kopi robusta telah banyak dilakukan (Murad et al., 2020);(Mayrowani, 2013b);(Sembiring et al., 2019); (Novita et al., 2010). Kebaharuan dalam penelitian ini adalah bahwa kajian mengenai adopsi standar pengolahan kopi berbasis IG oleh petani kopi robusta di Kabupaten Temanggung belum pernah dilakukan. Penelitian ini juga mengkaji sikap petani terhadap standar-standar pengolahan kopi secara detail berdasarkan standar IG Kopi Robusta Temanggung.

Penelitian ini bertujuan untuk menganalisis sikap petani terhadap standar pengolahan kopi berbasis IG, meliputi: metode pengolahan biji kopi, sortasi, pengeringan, pengukuran kadar air dan penyimpanan biji kopi. Dengan mengetahui sikap petani terhadap standar pengolahan kopi robusta diharapkan petani akan menerapkan atau mengadopsi secara optimal standar pengolahan kopi robusta Temanggung sehingga kualitas dan daya saingnya akan semakin baik.

\section{METODE PENELITIAN}

Penelitian ini merupakan penelitian deskriptif dan analitis dengan teknik survei. Penelitian deskriptif adalah penelitian yang bertujuan untuk mendeskripsikan (menggambarkan secara jelas dan terinci) mengenai aspek-

Jurnal Penyuluhan | Vol. 17 (02) 2020 | 219 
aspek yang relevan dengan fenomena yang menjadi ketertarikan peneliti. Penelitian ini bertujuan untuk mendapatkan gambaran mengenai sikap petani terhadap standar pengolahan kopi berbasis indikasi geografis. Peneliti memilih kabupaten Temanggung sebagai lokasi penelitian karena mempertimbangkan bahwa kabupaten Temanggung adalah produsen kopi terbesar di Jawa Tengah yaitu sebesar 10.45 ribu ton pada tahun 2018 (Jateng, 2019). Selain itu, kopi robusta mendominasi jenis kopi yang diusahakan di wilayah ini.

Jumlah responden yang digunakan dalam penelitian ini sebanyak 80 orang petani kopi robusta yang berada di lokasi sekretariat MPIG-KRT yaitu Kecamatan Kandangan Kabupaten Temanggung yang diambil dengan teknik random sampling dengan aplikasi randomizer. Adapun sebaran pengambilan sampel adalah sebagai berikut.

Tabel 1. Sebaran Sampel Penelitian

\begin{tabular}{llcc}
\hline No. & Desa & Jumlah Petani (n) & Jumlah responden (n) \\
\hline 1. & Caruban & 31 & 4 \\
2. & Baledu & 31 & 4 \\
3. & Rowo & 61 & 6 \\
4 & Malebo & 43 & 6 \\
5 & Gesing & 54 & 8 \\
6 & Banjarsari & 28 & 1 \\
7 & Blimbing & 24 & 3 \\
8 & Margolelo & 52 & 5 \\
9 & Wadas & 30 & 2 \\
10 & Kedungumpul & 30 & 5 \\
11 & Kandangan & 29 & 3 \\
12 & Samiranan & 121 & 14 \\
13 & Kembang Sari & 20 & 2 \\
14 & Ngemplak & 30 & 4 \\
15 & Tlego Pucang & 51 & 7 \\
16 & Kedawung & 25 & 6 \\
\hline & Total & 660 & 80 \\
\hline
\end{tabular}

Sumber: Analisis Data Primer 2018

Kopi robusta di Kecamatan Kandangan telah mendapatakan Juara Nasional untuk Cita Rasa Kopi. Alat pengumpulan data menggunakan kuesioner terstruktur dengan skala likert yaitu 1 yang berarti sangat tidak setuju hingga 5 yang berarti sangat setuju. Teknik pengumpulan data menggunakan wawancara dengan petani responden, observasi dan depth interview dengan staf Dinas Pertanian, BAPPEDA, Dinas Perindustrian, perdagangan, Koperasi dan UMKM serta dengan pengurus MPIG Kopi Robusta Temanggung. Analisis data menggunakan metode Rank Spearman dan hasil penelitian disajikan menggunakan tabel informatif atau distribusi frekuensi.

\section{HASIL DAN PEMBAHASAN}

Sikap petani terhadap standar pengolahan kopi berbasis indikasi geografis sangat penting untuk diketahui karena sikap akan mempengaruhi niat dan perilaku petani dalam menerapkannya (Ashari et al., 2016; Cahyono et al., 2020; Hamyana et al., 2020; Meena et al., 2009). Pada penelitian ini, sikap petani terhadap standar metode pengolahan pasca panen buah kopi petik merah disajikan pada Tabel 2. 
Tabel 2. Sikap Petani terhadap Standar Metode Pengolahan

\begin{tabular}{cllcc}
\hline \multicolumn{1}{c}{ Indikator } & \multicolumn{1}{c}{ Kriteria } & Kategori & Jumlah & Persentase \\
\hline $172,2-205$ & Sangat Setuju & Sangat Baik & 10 & 12,5 \\
$\mathbf{1 3 9 , 3}-\mathbf{1 7 2 , 1}$ & Setuju & Baik & $\mathbf{6 1}$ & $\mathbf{7 6 , 2 5}$ \\
$106,6-139,2$ & Netral & Cukup & 9 & 11,25 \\
$73,8-106,5$ & Tidak Setuju & Buruk & 0 & 0 \\
$41,0-73,7$ & Sangat Tidak Setuju & Sangat Buruk & 0 & 0 \\
\hline Jumlah & & & 80 & 100 \\
\hline
\end{tabular}

Sumber : Analisis Data Primer, 2018

Hasil analisis menunjukkan bahwa sebesar 76,25 persen petani memberikan sikap baik terhadap standar metode pengolahan sesuai IG Kopi Robusta Temanggung. Sikap setuju petani terhadap standar metode pengolahan menunjukkan hal positif terhadap faktor pengendalian mutu, mutu produk, dan SOP proses pengolahan. Buah kopi harus ditangani secara cepat menjadi bentuk yang lebih stabil agar aman untuk disimpan dalam jangka waktu tertentu. Kriteria mutu biji yang meliputi aspek fisik, cita rasa dan kebersihan serta aspek keseragaman dan konsistensi sangat ditentukan oleh perlakuan pada setiap tahapan proses produksinya. Oleh karena itu, tahapan proses dan spesifikasi peralatan pengolahan kopi yang menjamin mutu harus ditentukan secara jelas (Sulistyaningtyas, 2017). Standar yang ditentukan dalam IG Kopi Robusta Temanggung meliputi metode fisik, kualitas dan rasa, produksi (on farm), panen dan pascapanen, serta metode pengolahan (Ihsaniyati et al., 2020). Biji kopi yang dihasilkan petani perlu diolah dengan baik sehingga memenuhi persyaratan untuk diterima pasar di dalam negeri maupun di luar negeri (Prajogo et al., 2020) (Mayrowani, 2013a).

Kesadaran petani dalam mengolah buah kopi menjadi kopi HS dengan berbagai metode merupakan langkah awal dalam pengembangan proses pengolahan pasca panen buah kopi. Pengembangan yang dapat dilakukan antara lain pengembangan sumber daya manusia (Human Capital Development), pengembangan proses pengolahan, yang meliputi metode pengolahan, peralatan dan fasilitas pengolahan, serta prosedur pengolahan. Pengolahan kopi menjadi berbagai bentuk dengan berbagai cara akan menambah daya saing kopi tersebut (Yoga Priantara et al., 2017)

\section{Sikap Petani terhadap Standar Proses Pengolahan Biji Kopi Robusta}

Distribusi sikap petani terhadap indikator standar proses pengolahan tersaji pada Tabel 3.

Tabel 3. Distribusi Sikap Petani terhadap Beberapa Indikator Standar Proses Pengolahan

\begin{tabular}{|c|c|c|c|c|c|c|c|}
\hline No. & Pernyataan & $\begin{array}{l}\text { Sangat } \\
\text { Setuju }\end{array}$ & Setuju & Netral & $\begin{array}{l}\text { Tidak } \\
\text { Setuju }\end{array}$ & $\begin{array}{l}\text { Sangat } \\
\text { Tidak } \\
\text { Setuju }\end{array}$ & Jumlah \\
\hline 1. & $\begin{array}{l}\text { Pengolahan buah kopi yang } \\
\text { dipanen dilakukan di UPH (Unit } \\
\text { Pengolahan Hasil) }\end{array}$ & 2 & 25 & 26 & 27 & 0 & 80 \\
\hline 2. & $\begin{array}{l}\text { Pengolahan kopi (olah basah, } \\
\text { olah kering, kopi madu) harus } \\
\text { dilakukan berurutan dan sesuai } \\
\text { standar yang ditetapkan }\end{array}$ & 14 & 46 & 17 & 3 & 0 & 80 \\
\hline 3. & $\begin{array}{l}\text { Pengolahan buah kopi (olah } \\
\text { basah, olah kering, kopi madu) } \\
\text { diawali dengan sortasi } \\
\text { kematangan buah, buah yang } \\
\text { belum merah dipisahkan }\end{array}$ & 15 & 44 & 16 & 5 & 0 & 80 \\
\hline
\end{tabular}

Sumber : Analisis Data Primer, 2018

Sebagian besar petani (sebanyak 66,25 persen) masih belum melakukan proses pengolahan di Unit Pengolahan Hasil (UPH) dan sebanyak 32,25 persen sudah melakukan pengolahan buah kopi di UPH. Poin 2 dan 3, menunjukkan sikap petani setuju terhadap SOP dan sortasi berdasarkan kematangan buah. Secara garis besar, 
petani kopi di Temanggung mengetahui bahwa SOP dan sortasi merupakan bagian yang penting pada proses pengolahan pasca panen buah kopi. Pengolahan biji kopi menjadi wujud lain akan meningkatkan nilai tambah kopi, misalnya dari kopi gelondong merah segar menjadi kopi ose (green bean), pengolahan kopi ose menjadi kopi bubuk (Atmaja et al., 2015).

\section{Sikap Petani terhadap Standar Sortasi Biji Kopi Robusta}

Pendalaman data mengenai sikap petani terhadap proses sortasi disajikan pada Tabel 4.

Tabel 4. Sikap Petani terhadap Standar Sortasi Buah dan Biji Kopi

\begin{tabular}{|c|c|c|c|c|c|c|c|}
\hline No. & Pernyataan & $\begin{array}{l}\text { Sangat } \\
\text { Setuju }\end{array}$ & Setuju & Netral & $\begin{array}{l}\text { Tidak } \\
\text { Setuju }\end{array}$ & $\begin{array}{l}\text { Sangat } \\
\text { Tidak } \\
\text { Setuju }\end{array}$ & Jumlah \\
\hline 1. & $\begin{array}{l}\text { Sortasi dilakukan untuk memperoleh } \\
95 \text { persen buah kopi merah segar dan } \\
\text { sehat (BMSS) dan maksimal } 5 \text { persen } \\
\text { buah kopi berwarna kuning (olah } \\
\text { basah, olah kering) }\end{array}$ & 12 & 54 & 10 & 4 & 0 & 80 \\
\hline 2. & $\begin{array}{l}\text { Sortasi dilakukan untuk memperoleh } \\
100 \text { persen buah kopi merah segar } \\
\text { dan sehat (BMSS) untuk kopi madu }\end{array}$ & 20 & 46 & 8 & 5 & 1 & 80 \\
\hline 3. & $\begin{array}{l}\text { Buah kopi berwarna hijau atau hitam } \\
\text { tidak boleh digunakan }\end{array}$ & 14 & 37 & 15 & 13 & 1 & 80 \\
\hline 4. & $\begin{array}{l}\text { Hasil sortasi yang berupa buah-buah } \\
\text { yang belum merah tetap dapat diolah } \\
\text { tetapi tidak boleh dijual dengan nama } \\
\text { Kopi Robusta Temanggung }\end{array}$ & 12 & 29 & 28 & 9 & 2 & 80 \\
\hline 5. & $\begin{array}{l}\text { Buah kopi yang mengambang tidak } \\
\text { boleh digunakan untuk menghasilkan } \\
\text { Kopi Robusta Temanggung }\end{array}$ & 13 & 37 & 23 & 7 & 0 & 80 \\
\hline 7. & $\begin{array}{l}\text { Buah kopi yang telah di pulper (biji } \\
\text { kopi HS basah) selanjutnya harus } \\
\text { dirambang kembali untuk } \\
\text { memisahkkan biji kopi HS basah } \\
\text { yang bernas dengan yang tidak } \\
\text { sempurna (olah basah) }\end{array}$ & 9 & 42 & 23 & 6 & 0 & 80 \\
\hline 8. & $\begin{array}{l}\text { Biji kopi HS basah yang tenggelam } \\
\text { disimpan dalam bak fermentasi } \\
\text { selama } 12-36 \text { jam (olah basah) }\end{array}$ & 6 & 38 & 29 & 7 & 0 & 80 \\
\hline
\end{tabular}

Sumber: Analisis Data Primer, 2018

Tabel ini menunjukkan distribusi sikap petani terhadap indikator standar sortasi buah kopi. Sortasi Buah kopi Merah Segar dan Sehat (BMSS) sudah dilakukan oleh petani kopi di Temanggung. Sekitar 75-82,5 persen petani memiliki sikap setuju dan sangat setuju mengenai sortasi buah kopi untuk mendapatkan BMSS. Sikap positif petani mengenai pentingnya sortasi mengidikasikan pengetahuan petani mengenai mutu produk akhir dipengaruhi oleh mutu bahan baku, yaitu buah kopi merah. Sikap petani terhadap sortasi dan pemanfaatan buah kopi belum merah dan hijau menunjukkan sikap setuju dan sangat setuju. Pada distribusi data sikap petani kopi terhadap sortasi dan pemanfaatan buah kopi belum merah dan hijau, sebanyak 63,75 persen petani kopi setuju jika kopi hijau tidak boleh digunakan dalam proses pengolahan selanjutnya. Petani kopi yang setuju bahwa hasil sortasi buah kopi yang belum merah tetap dapat diolah tetapi tidak boleh dijual dengan nama Kopi Robusta Temanggung sebanyak 51.25 persen petani.

Pada data tersebut, masih ada 48,75 persen petani menunjukkan sikap netral maupun tidak setuju jika buah kopi non merah tidak dapat diproses dan dijual dengan nama Kopi Robusta Temanggung. Faktor-faktor yang mempengaruhi sikap petani tersebut perlu ditelaah dan dikaji untuk dapat diketahui penyebab dan solusi agar petani dapat menunjukkan sikap setuju. Poin 5-8 pada Tabel 3 menunjukkan sikap petani tidak lebih dari 50 persen setuju mengenai proses sortasi basah, penghilangan daging buah (pulping), dan proses pengolahan 
setelah sortasi basah. Sebanyak 7,5-13,75 persen petani masih menunjukkan sikap tidak setuju. Hal ini menjadi problematika ketika mutu produk akhir sangat dipengaruhi oleh kualitas bahan baku dan proses pengolahan pasca panen buah kopi. Untuk meningkatkan kualitas produk akhir dan sustainability proses produksi buah kopi di Temanggung, petani harus memiliki satu kesamaan visi dan misi, kesetaraan pemahaman dan pengetahuan mengenai SOP pengolahan kopi, dan memiliki sistem kerja kelompok tani sehingga kemajuan dan pengembangan produk kopi di Temanggung dapat dilaksanakan dan diupayakan.

\section{Sikap Petani Mengenai Standar Pengeringan Kopi Robusta}

Sikap petani mengenai teknik dan metode pengeringan kopi HS dapat dilihat pada Tabel 5.

Tabel 5. Distribusi Sikap Petani terhadap Pengeringan Kopi Robusta

\begin{tabular}{|c|c|c|c|c|c|c|c|c|}
\hline No. & \multicolumn{2}{|l|}{ Pernyataan } & $\begin{array}{l}\text { Sangat } \\
\text { Setuju }\end{array}$ & Setuju & Netral & $\begin{array}{l}\text { Tidak } \\
\text { Setuju }\end{array}$ & $\begin{array}{l}\text { Sangat } \\
\text { Tidak } \\
\text { Setuju }\end{array}$ & Jumlah \\
\hline 1. & $\begin{array}{l}\text { Biji kopi HS basah dijemur di b } \\
\text { sinar matahari atau pengering b } \\
\text { bila tidak terdapat cukup matah } \\
\text { (olah basah) }\end{array}$ & $\begin{array}{l}\text { awah } \\
\text { uatan } \\
\text { ari }\end{array}$ & 12 & 54 & 8 & 5 & 1 & 80 \\
\hline 2. & $\begin{array}{l}\text { Saat penjemuran/pengeringan, } \\
\text { kopi dihampar setebal } 5-7 \mathrm{~cm}\end{array}$ & & 2 & 24 & 18 & 33 & 3 & 80 \\
\hline 3. & $\begin{array}{l}\text { Saat penjemuran/pengeringan, } \\
\text { dilakukan pembalikan sehari } 4\end{array}$ & & 12 & 42 & 21 & 5 & 0 & 80 \\
\hline 4. & $\begin{array}{l}\text { Biji kopi dikeringkan selama } \\
\text { minimal } 3 \text { hari sampai madu pa } \\
\text { kulit tanduk mengering (kopi m }\end{array}$ & $\begin{array}{l}\text { da } \\
\text { adu) }\end{array}$ & 11 & 47 & 18 & 4 & 0 & 80 \\
\hline 5. & $\begin{array}{l}\text { Biji kopi yang dijemur/dikering } \\
\text { harus dihindarkan dari diinjak }\end{array}$ & & 13 & 38 & 15 & 14 & 0 & 80 \\
\hline 6. & $\begin{array}{l}\text { Tempat penjemuran harus jauh } \\
\text { dari tempat sampah, kandang } \\
\text { ternak, sumber kontaminasi }\end{array}$ & 22 & 55 & & 3 & 0 & 0 & 80 \\
\hline 7. & $\begin{array}{l}\text { Harus menghindari } \\
\text { mencampur biji kopi HS yang } \\
\text { sudah kering dengan yang } \\
\text { masih basah }\end{array}$ & 20 & 55 & & 5 & 0 & 0 & 80 \\
\hline 8. & $\begin{array}{l}\text { Penjemuran kopi dilakukan } \\
\text { hingga kadar air maksimal } 12 \\
\text { persen }\end{array}$ & 9 & 45 & & 22 & 4 & 0 & 80 \\
\hline
\end{tabular}

Sumber: Analisis Data Primer, 2018

Rata-rata lebih dari 50 persen petani menunjukkan sikap petani setuju dengan SOP proses pengeringan kopi sesuai standar IG. Dengan sikap positif terhadap teknik pengeringan tersebut, diharapkan petani dapat memenuhi standar mutu produk hasil pengeringan dan menjaga kualitas kadar air kopi. Akan tetapi pada poin 2, sebanyak 41,25 persen petani tidak setuju mengenai ketebalan hamparan. Hal ini disebabkan ketebalan hamparan biji kopi saat pengeringan disesuaikan dengan kebiasaan petani. Proses pengeringan merupakan hal yang sangat penting pada pengolahan kopi karena tanpa pengeringan yang baik kualitas biji kopi tidak akan maksimal. Pengeringan bertujuan untuk mengurangi kadar air biji kopi hingga mencapai standar mutu dan kadar air yang diinginkan dan sesuai (Dwi Santoso, 2018). Kopi dikeringkan dengan meningkatkan suhu biji kopi untuk menguapkan air (Ollika Fufa et al., 2019) Untuk itu penting untuk memberikan edukasi bagi petani mengenai proses pengeringan yang sesuai standar IG.

\section{Sikap Petani terhadap Standar Pengukuran Kadar Air Biji Kopi}

Pengukuran kadar air selama ini dilakukan tanpa alat ukur tetapi dengan perasaan dengan menggigit biji kopi dan mendengarkan bunyi gemerisik biji kopi saat menggoyang-goyangkan biji kopi saat dijemur. Sikap petani mengenai teknik dan metode pengukuran kadar air biji kopi disajikan pada Tabel 6. 
Tabel 6. Distribusi Sikap Petani Terhadap Standar Pengukuran Kadar Air Biji Kopi

\begin{tabular}{llcccccc}
\hline No. & \multicolumn{1}{c}{ Pernyataan } & $\begin{array}{c}\text { Sangat } \\
\text { Setuju }\end{array}$ & Setuju & Netral & $\begin{array}{c}\text { Tidak } \\
\text { Setuju }\end{array}$ & $\begin{array}{c}\text { Sangat } \\
\text { Tidak } \\
\text { Setuju }\end{array}$ & Jumlah \\
\hline 1. & $\begin{array}{l}\text { Pengukuran kadar air dilakukan dengan } \\
\text { alat ukur kadar air }\end{array}$ & 8 & 29 & 27 & 16 & 0 & 80 \\
2. $\begin{array}{l}\text { Pengukuran kadar air menggunakan } \\
\text { perasaan (seperti : mengguncang- } \\
\text { guncangkan biji kopi HS yang } \\
\text { dikeringkan, menggigit biji kopi) juga } \\
\text { dapat memperkirakan kadar air } \\
\text { maksimal 12 persen }\end{array}$ & 9 & 54 & 16 & 1 & 0 & 80 \\
\hline
\end{tabular}

Sumber: Analisis Data Primer, 2018

Petani belum menilai pengukuran kadar air menggunakan alat ukur baik atau perlu untuk dilakukan. Hal ini menjadi tantangan tersendiri untuk meningkatkan kesadaran dan motivasi petani untuk menggunakan alat ukur kadar air untuk validitas dan konsistensi hasil pengukuran. Rendahnya mutu kopi ditingkat petani terutama disebabkan oleh adanya masalah pasca panen kopi yang ditemui dilapangan antara lain kadar air yang tinggi, hal ini nantinya akan memicu pertumbuhan jamur, sehingga pada tingkat lanjut akan berpengaruh terhadap cita rasa (Mayrowani, 2013a).

\section{Sikap Petani terhadap Standar Penyimpanan Biji Kopi Kering}

Metode penyimpanan biji kopi akan mempengaruhi kualitas biji kopi dan umur simpan. Untuk itu penting bagi petani memperhatikan metode atau standar penyimpanan biji kopi yang benar. Cara dan tempat untuk menyimpan hasil yang tidak memadai menyebabkan meningkatnya kadar kotoran dan kadar air (Murad et al., 2020). Tabel 7 berikut mempresentasikan data distribusi sikap petani terhadap metode penyimpanan biji kopi kering.

Tabel 7. Distribusi Sikap Petani terhadap Standar Penyimpanan Biji Kopi

\begin{tabular}{|c|c|c|c|c|c|c|c|}
\hline No. & Pernyataan & $\begin{array}{l}\text { Sangat } \\
\text { Setuju }\end{array}$ & Setuju & Netral & $\begin{array}{l}\text { Tidak } \\
\text { Setuju }\end{array}$ & $\begin{array}{l}\text { Sangat } \\
\text { Tidak } \\
\text { Setuju }\end{array}$ & Jumlah \\
\hline 1. & $\begin{array}{l}\text { Biji kopi HS yang sudah kering harus } \\
\text { dikemas dengan wadah (plastik, } \\
\text { karung) yang baru dan bersih }\end{array}$ & 19 & 49 & 8 & 3 & 1 & 80 \\
\hline 2. & $\begin{array}{l}\text { Karung plastik disimpan dalam } \\
\text { gudang yang bersih, kering, beraerasi } \\
\text { baik, bebas dari binatang dan benda- } \\
\text { benda berbau tajam }\end{array}$ & 16 & 55 & 6 & 3 & 0 & 80 \\
\hline 3. & $\begin{array}{l}\text { Karung plastik yang disimpan di } \\
\text { gudang harus diberi alas }\end{array}$ & 21 & 52 & 6 & 1 & 0 & 80 \\
\hline 4. & $\begin{array}{l}\text { Karung plastik yang disimpan di } \\
\text { gudang diberi jarak dari dinding } \\
\text { gudang }\end{array}$ & 15 & 50 & 12 & 3 & 0 & 80 \\
\hline 5. & $\begin{array}{l}\text { Biji kopi kering yang akan dijual } \\
\text { dikupas kulitnya menggunakan mesin } \\
\text { huller (olah kering) }\end{array}$ & 20 & 53 & 7 & 0 & 0 & 80 \\
\hline 6. & $\begin{array}{l}\text { Biji kopi kering yang sudah terkelupas } \\
\text { kulitnya (biji ose) harus disortasi dan } \\
\text { diayak untuk membuang kulit yang } \\
\text { masih terbawa dan biji yang pecah } \\
\text { (olah kering) }\end{array}$ & 13 & 52 & 12 & 3 & 0 & 80 \\
\hline 7. & $\begin{array}{l}\text { Biji kopi ose disimpan dalam wadah } \\
\text { yang bersih dan baru (olah kering) }\end{array}$ & 10 & 58 & 9 & 3 & 0 & 80 \\
\hline 8. & $\begin{array}{l}\text { Biji kopi ose harus ditimbang dan } \\
\text { diikat sebelum disimpan (olah kering) }\end{array}$ & 7 & 52 & 16 & 5 & 0 & 80 \\
\hline
\end{tabular}




\begin{tabular}{cccccccc}
\hline No. & Pernyataan & $\begin{array}{c}\text { Sangat } \\
\text { Setuju }\end{array}$ & Setuju & Netral & $\begin{array}{c}\text { Tidak } \\
\text { Setuju }\end{array}$ & $\begin{array}{c}\text { Sangat } \\
\text { Tidak } \\
\text { Setuju }\end{array}$ & Jumlah \\
\hline $9 . \quad \begin{array}{l}\text { Biji kopi ose yang telah ditimbang dan } \\
\text { diikat harus dicatat }\end{array}$ & 11 & 38 & 23 & 7 & 1 & 80 \\
\hline Sumber: & & & & & & \\
\hline
\end{tabular}

Sumber : Analisis Data Primer, 2018

Pada data tersebut, menunjukkan lebih dari 50 persen petani setuju dengan SOP dan metode penyimpanan biji kopi kering sesuai standar IG. Hal ini merupakan sikap positif yang mendukung pengendalian mutu biji kopi kering. Meskipun ada beberapa petani yang masih menunjukkan sikap tidak setuju pada cara penyimpanan yang baik, misalnya pada cara penyimpanan biji kopi dengan memberikan jarak antar karung plastik kopi, penggunaan karung plastik yang baru dan bersih, penyimpanan dalam gudang yang bersih dan kering. Sikap petani tersebut perlu diteliti lebih lanjut terhadap tingkat kepemahaman petani dan sikap keingintahuan cara penyimpanan biji kopi kering yang baik. Pengembangan psikologis petani dengan melihat tipikal geografis terhadap kondisi lingkungan sebagai parameter yang harus dijaga dan dikontrol, misalnya lokasi geografis akan mempengaruhi parameter kelembaban udara dan suhu tempat penyimpanan, adanya hewan pengerat, dan sirkulasi udara.

\section{KESIMPULAN}

Sebagian besar petani memilik sikap baik terhadap metode pengolahan sesuai standar IG, standar sortasi, pengeringan biji kopi dan penyimpanan biji kopi sesuai standar IG. Di sisi lain, sebagian besar masih belum melakukan proses pengolahan di Unit Pengolahan Hasil dan melakukan pengukuran kadar air secara manual. Untuk meningkatkan implementasi standar pengolahan memerlukan sosialisasi, training dan pendampingan secara intensif dalam menerapkan standar metode pengolahan kopi, sortasi, pengeringan biji kopi dan penyimpanan biji kopi berbasis indikasi geografis. Selain itu, diperlukan fasilitasi infrastruktur berupa Unit Pengolahan Hasil yang lebih memadai dari sisi jumlah dan kapasitas diperlukan untuk memotivasi petani kopi menerapkan standar pengolahan kopi berbasis IG. Introduksi alat ukur kadar biji kopi dan edukasi diperlukan untuk memotivasi petani beralih ke teknik pengukuran yang sesuai standar IG yaitu menggunakan alat ukur. Akhirnya, diperlukan kolaborasi antar stakeholder khususnya Dinas Pertanian, MPIG, Gapoktan dan Petani dalam implementasi dan diseminasi penerapan standar pengolahan kopi robusta berbasis IG.

\section{UCAPAN TERIMA KASIH}

Penulis mengucapkan terima kasih kepada Universitas Sebelas Maret yang telah membiayai pelaksanaan penelitian ini. Penulis juga berterima kasih kepada pemerintah Kabupaten Temanggung, Dinas Pertanian dan Perkebunan, Dinas Perindustrian, Perdagangan dan UMKM, MPIG, Ketua Gakpoktan dan Petani kopi robusta Temanggung untuk informasi dan kerjasama yang baik.

\section{DAFTAR PUSTAKA}

Ajzen, I., \& Fishbein, M. (1981). Attitudes and voting behaviour: An application of the theory of reasoned action. In Progress in applied social psychology (pp. 95-125, Vol. 1).

Ashari, Sharifuddin, J., Mohammed, Z. A., \& Rika, T. (2016). Rice Farmers' Perception And Attitude Toward Organic Farming Adoption Persepsi dan Sikap Petani Padi terhadap Niat untuk Mengadopsi. Jurnal Agro Ekonomi, 34(1), 35-46.

Atmaja, I., Tamba, I., \& Kardi, C. (2015). Peningkatan Pendapatan Petani Kopi Arabika Peserta Unit Pengolahan Hasil (UPH)(Kasus Di Desa Belok Sidan Kecamatan Petang Kabupaten. Jurnal Agrimeta, 5(10), 32-42. http://jurnal.unmas.ac.id/index.php/agrimeta/article/view/134

Badan Pusat Statistik Provinsi Jawa Tengah. (2019). Jawa Tengah Dalam Angka 2019. 689.

Cahyono, B., Setyowati, R., \& Ihsaniyati, H. (2020). Adopsi Cyber Extension oleh Penyuluh Pertanian Lapangan ( PPL ) dan Faktor yang Mempengaruhi Adoption of Cyber Extension by Agricultural Extension Workers ( PPL ) and Factors Affecting. Jurnal Penyuluhan, 16(02), 240-249.

Dos Santos, D. A. M., Lobo, J. da S. T., Araújo, L. M., Deliza, R., \& Marcellini, P. S. (2015). Perfil livre, 
aceitação e intenção de compra na avaliação de diferentes formulações de biscoitos. Ciencia e Agrotecnologia, 39(6), 613-623. https://doi.org/10.1590/S1413-70542015000600008

Duarte, G. S., Pereira, A. A., \& Farah, A. (2010). Chlorogenic acids and other relevant compounds in Brazilian coffees processed by semi-dry and wet post-harvesting methods. Food Chemistry, 118(3), 851-855. https://doi.org/10.1016/j.foodchem.2009.05.042

Dwi Santoso, S. E. (2018). Pengaruh Metode Pengeringan Terhadap Karakteristik dan Sifat Organoleptik Biji Kopi Arabika ( Coffeae Arabica) Dan Biji Kopi Robusta (Coffeae Cannephora). Jurnal Rona Teknik Pertanian, 11(2), 50-56. http://jurnal.unsyiah.ac.id/RTP/article/view/11726/11473

Hamdouche, Y., Meile, J. C., Nganou, D. N., Durand, N., Teyssier, C., \& Montet, D. (2016). Discrimination of post-harvest coffee processing methods by microbial ecology analyses. Food Control, 65, 112-120. https://doi.org/10.1016/j.foodcont.2016.01.022

Hamyana, H., Nurdiasari, D., \& Kurniasari, I. (2020). Factors That Influence Adoption of Jajar Legowo Planting System in Sumber Makmur Farmer Group Kuwu Village, Balerejo, Madiun. Jurnal Penyuluhan, 16(1), 64-77. https://doi.org/10.25015/16202027767

Ihsaniyati, H., Setyowati, N., \& Pardono. (2020). Strategy of Improving the Farmers' Adoption to Temanggung Robusta Coffee's Geographical Indication Standard. IOP Conference Series: Earth and Environmental Science, 519(1). https://doi.org/10.1088/1755-1315/519/1/012036

Jateng, B. (2019). Produksi Perkebunan Menurut Kabupaten / Kota dan Jenis Tanaman di Provinsi Jawa Tengah ( ribu ton ), 2018 dan 2019 Production of Estate by Regency / Municipality and Type of Crops in Jawa Tengah Province ( thousands ton ), 2018 and 2019 Regency / Municipa. BPS Jawa Tengah. https://jateng.bps.go.id/statictable/2020/07/22/1936/produksi-perkebunan-menurut-kabupaten-kotadan-jenis-tanaman-di-provinsi-jawa-tengah-ribu-ton-2018-dan-2019.html

Mayrowani, H. (2013a). Kebijakan Penyediaan Teknologi Pascapanen Kopi dan Masalah Pengembangannya. Forum Penelitian Agro Ekonomi, 31(1), 31. https://doi.org/10.21082/fae.v31n1.2013.31-49

Mayrowani, H. (2013b). MASALAH PENGEMBANGANNYA Policies on Coffee Post-Harvest Technology Development and Its Development Issues. 31-50.

Meena, M. S., Ashwani, K., Singh, K. M., \& Meena, H. R. (2009). Farmers' attitude towards post-harvest issues of horticultural crops. Indian Research Journal of Extension Education, 9(3), 15-19. http://search.ebscohost.com/login.aspx?direct=true \&db=lah\&AN=20103353431\&site=ehostlive\%5Cnhttp://www.seea.org.in/vol9-3-2009/04.pdf\%5Cnemail: ms101@sify.com

Murad, M., Sukmawaty, S., Sabani, R., Ansar, A., \& Kurniawan, H. (2020). Introduksi Ttg Pasca Panen Dan Pengolahan Kopi Pada Industri Rumah Tangga Guna Meningkatkan Nilai Tambah Di Kecamatan Tanjung Kabupaten Lombok Utara. Jurnal Ilmiah Abdi Mas TPB Unram, 2(1). https://doi.org/10.29303/amtpb.v2i1.38

Novita, E., Syarief, R., Noor, E., \& Mulato, S. (2010). Peningkatan Mutu Biji Kopi Rakyat dengan Pengolahan Semi Basah Berbasis Produksi Bersih. Agrotek, 4(1), 76-90. http://jurnal.unej.ac.id/index.php/JAGT/article/view/2316

Ollika Fufa, B., Bekele Etana, M., \& Chewaka Aga, M. (2019). Review on Post-Harvest and Green Bean Coffee Processing in Ethiopia. Acta Scientific Agriculture, 3(7), 157-162. https://doi.org/10.31080/asag.2019.03.0536

Prajogo, U., Lutfi, M., Liana, Y., \& Adi, S. (2020). Evaluation of post-harvest coffee to conform with good manufacturing practices (GMP) to develop entrepreneurship. IOP Conference Series: Earth and Environmental Science, 475(1). https://doi.org/10.1088/1755-1315/475/1/012046

Pratiwi, R. R. (2016). Economics Development Analysis Journal. 5(2), 207-216. http://journal.unnes.ac.id/sju/index.php/eda

Sanaky, H. A., \& Nashori, F. (2018). Peningkatan Dan Pengembangan Produk Olahan Kopi Di Desa Brunosari. AJIE-Asian Journal of Innovation and Entrepreneurship, 03(03), 2477-3824. 
Scholz, M. B. dos S., Prudencio, S. H., Kitzberger, C. S. G., \& Silva, R. S. dos S. F. da. (2019). Physicochemical characteristics and sensory attributes of coffee beans submitted to two post-harvest processes. Journal of Food Measurement and Characterization, 13(1), 831-839. https://doi.org/10.1007/s11694018-9995-x

Sembiring, A. C., Sitanggang, D., Purnasari, N., Budiman, I., Teknologi, F., \& Indonesia, U. P. (2019). Pengolahan Pasca Panen Di Desa Lingga Kabupaten Karo. 8(2).

Sulistyaningtyas, A. (2017). Prosiding Seminar Nasional Publikasi Hasil-Hasil Penelitian dan Pengabdian Masyarakat 'Implementasi Penelitian dan Pengabdian Masyarakat Untuk Peningkatan Kekayaan Intelektual' PENTINGNYA PENGOLAHAN BASAH (WET PROCESSING) BUAH KOPI ROBUSTA (Coffea robusta. Pentingnya Pengolahan Basah (Wet Processing) Buah Kopi Robusta (Coffea Var. Robusta) Untuk Menurunkan Resiko Kecacatan Biji Hijau Saat Coffe Grading, 90-94.

Sumarjo, N. S., \& Ihsaniyati, H. I. (2020). PETANI KOPI ROBUSTA DI KABUPATEN TEMANGGUNG Adoption Of Geographical Indication Standards By Robusta Coffee Farmers In Temanggung District. AGRISEP, 19(1), 1-14. https://doi.org/10.31186/jagrisep.19.1.1-14

Yoga Priantara, I., Mulyani, S., \& Satriawan, I. (2017). Analisis Nilai Tambah Pengolahan Kopi Arabika Kintamani Bangli. Jurnal Rekayasa Dan Manajemen Agroindustri, 4(4), 33 - 42. 